\section{What constitutes the most cautious approach for a pregnant person with weak D type 4.0?}

A recent CMAJ Practice article ${ }^{1}$ on modern Rhesus (Rh) typing in transfusion and pregnancy and its associated correspondence ${ }^{2}$ prompted a productive discussion on safe recommendations for pregnant patients with a weak $D$ type 4.0 allele, originally described in $2000 .^{3}$ The differing approaches ${ }^{1,2}$ represent the personal views of the respective authors. Based on our review of 20 years' worth of literature on this specialized topic, we have agreed on the following 5 statements:

1. No published case reports have documented adverse clinical effects, such as hemolysis, among pregnant people with weak $D$ type 4.0 caused by an allo- or auto-anti-D.

2. Similarly, no published case reports have documented adverse clinical effects, such as anemia or jaundice, among fetuses or newborns caused by such a mother's allo- or auto-anti-D.

3. No published evidence has shown that $\mathrm{Rh}$ immunoglobulin (Rhlg) is clinically effective in an individual with weak $D$ type 4.0 (e.g., for preventing anti-D formation); Rhlg can cause a positive direct antiglobulin test, which does not imply clinical harm.

4. The weak $D$ type 4.0 phenotype may be associated with a proportionately larger number of anti-D than most other weak D types. ${ }^{4-6}$ The nature of these antibodies has not been well characterized (i.e., allo- v. autoantibody). ${ }^{6} \mathrm{~A}$ fraction of all people with a weak $D$ type 4.0 are routinely typed as normal RhD-positive and do not receive Rhlg.,7,8
5. The decision of whether or not to use Rhlg or RhD-negative transfusion in such mothers should be based on national guidelines. ${ }^{9}$ Both approaches have been adopted by expert groups ${ }^{2,6,8-10}$ and are considered safe. The decision may still depend on an individual patient's circumstances. ${ }^{11}$ If providers are unsure, consultation with a transfusion medicine physician or perinatal immunohematology reference laboratory is recommended..$^{1,10}$

\section{Willy Albert Flegel MD}

Transfusion medicine specialist, chief of Laboratory Services section, NIH Clinical Center, National Institutes of Health, Bethesda, Md.

\section{Melanie Bodnar MD}

Hematopathologist, transfusion medicine specialist, Canadian Blood Services, Edmonton, Alta.

\section{Gwen Clarke MD}

Hematopathologist, transfusion medicine specialist, associate medical director of

Donor and Clinical Services, Canadian

Blood Services, Edmonton, Alta.

\section{Judith Hannon MD}

Hematopathologist, transfusion medicine specialist, chair of Perinatal Advisory

Council, Canadian Blood Services,

Edmonton, Alta.

\section{Lani Lieberman MD}

Pediatric hematologist, transfusion medicine specialist, chair of Canadian Obstetric and Pediatric Transfusion Network, University Health Network, Toronto, Ont.

- Cite as: CMAJ 2021 June 14;193:E916. doi: $10.1503 / \mathrm{cmaj} .78986$

\section{References}

1. Flegel WA. Modern Rhesus (Rh) typing in transfusion and pregnancy. CMAJ 2021;193:E124.
2. Bodnar M, Hannon J, Lieberman LRE. Modern Rhesus (Rh) typing in transfusion and pregnancy [letter]. CMAJ 2021 Apr. 06. Available: www.cmaj. ca/content/193/4/E124/tab-e-letters\#re-modern -rhesus-rh-typing-in-transfusion-and-pregnancy (accessed 2021 Apr. 26)

3. Wagner FF, Frohmajer A, Ladewig B, et al. Weak $D$ alleles express distinct phenotypes. Blood 2000;95:2699-708.

4. Flegel WA. How I manage donors and patients with a weak D phenotype. Curr Opin Hematol 2006;13: 476-83.

5. Pham BN, Roussel M, Gien D, et al. Molecular analysis of patients with weak $D$ and serologic analysis of those with anti-D (excluding type 1 and type 2). Immunohematology 2013;29:55-62.

6. Westhoff CM, Nance S, Lomas-Francis C, et al. Experience with RHD*weak D type 4.0 in the USA. Blood Transfus 2019;17:91-3.

7. Yu X, Wagner FF, Witter B, et al. Outliers in RhD membrane integration are explained by variant RH haplotypes. Transfusion 2006;46:1343-51.

8. Ouchari M, Srivastava K, Romdhane H, et al. Transfusion strategy for weak D Type 4.0 based on RHD alleles and RH haplotypes in Tunisia. Transfusion 2018;58:306-12.

9. Flegel WA, Peyrard T, Chiaroni J, et al. A proposal for a rational transfusion strategy in patients of European and North African descent with weak D type 4.0 and 4.1 phenotypes. Blood Transfus 2019;17:89-90.

10. Flegel WA, Denomme GA, Queenan JT, et al. It's time to phase out "serologic weak D phenotype" and resolve D types with RHD genotyping including weak D type 4. Transfusion 2020;60:855-9.

11. Yin Q, Srivastava K, Brust DG, et al. Transfusion support during childbirth for a woman with anti$\mathrm{U}$ and the RHD*weak D type 4.0 allele. Immunohematology 2021;37:1-4.

Competing interests: None declared.

Funding: Willy Albert Flegel is supported by the $\mathrm{NIH}$ Clinical Center, Intramural Research Program, ID ZIC CL002128.

Content licence: This is an Open Access article distributed in accordance with the terms of the Creative Commons Attribution (CC BY-NC-ND 4.0) licence, which permits use, distribution and reproduction in any medium, provided that the original publication is properly cited, the use is noncommercial (i.e., research or educational use), and no modifications or adaptations are made. See: https://creativecommons.org/ licenses/by-nc-nd/4.0/

Disclaimer: The views expressed do not necessarily represent the views of the National Institutes of Health, the Department of Health and Human Services, or the U.S. Federal Government. 